\title{
Implications of the Molybdenum Coordination Environment in MFI Zeolites on Methane Dehydroaromatisation Performance
}

\author{
Miren Agote-Arán, ${ }^{[a, b]}$ Rachel E. Fletcher, ${ }^{[a]}$ Martha Briceno, ${ }^{[c]}$ Anna B. Kroner, ${ }^{[b]}$ Igor V. Sazanovich, ${ }^{[d]}$ \\ Ben Slater, ${ }^{\left[{ }^{[a]}\right.}$ María E. Rivas, ${ }^{[c]}$ Andrew W.J. Smith, ${ }^{[c]}$ Paul Collier, ${ }^{[c]}$ Inés Lezcano-González, ${ }^{*}\left[{ }^{[a,}\right.$ Andrew \\ M. Beale*[a,e]
}

\begin{abstract}
The structure and activity of Mo/Silicalite-1 (MFI, Si/AI $=\infty$ ) were compared to $\mathrm{Mo} / \mathrm{H}-\mathrm{ZSM}-5(\mathrm{MFI}, \mathrm{Si} / \mathrm{Al}=15)$, a widely studied catalyst for methane dehydroaromatisation (MDA). The anchoring mode of Mo was evaluated by in situ X-ray absorption spectroscopy (XAS) and density functional theory (DFT). The results showed that in $\mathrm{Mo} /$ Silicalite-1, calcination leads to dispersion of $\mathrm{MoO}_{3}$ precursor into tetrahedral Mo-oxo species in close proximity to the microporous framework. A weaker interaction of the Mo-oxo species with the Silicalite- 1 was determined by XAS and DFT. While both catalysts are active for MDA, Mo/Silicalite-1 undergoes rapid deactivation which was attributed to a faster sintering of Mo species leading to the accumulation of carbon deposits on the zeolite outer surface. The results shed light onto the nature of the Mo structure(s) while evidencing the importance of framework $\mathrm{Al}$ in stabilising active Mo species under MDA conditions.
\end{abstract}

\section{Introduction}

Methane dehydroaromatisation (MDA) is a promising route for the valorisation of $\mathrm{CH}_{4}$ into higher value chemicals as it converts methane directly into aromatics and light hydrocarbons giving $\mathrm{H}_{2}$

[a] Dr. M. Agote-Arán, Dr. R. E. Fletcher, Prof. B. Slater, Dr. I. Lezcano González, Prof. A. M. Beale

Chemistry Department, University College of London

Gordon Street, London, WC1H 0AJ (UK)

E-mail: i.lezcano-gonzalez@ucl.ac.uk

E-mail: Andrew.Beale@ucl.ac.uk

[b] Dr. M. Agote-Arán and Dr. A. B. Kroner

Diamond Light Source Ltd, Harwell Science and Innovation Campus, Didcot, OX11 ODEU (UK)

[c] Dr. M. Briceno, Dr. M. E. Rivas, Dr. A. W. J. Smith, Dr. P. Collier Johnson Matthey Technology Centre, Blount's Court, Sonning Common, Reading RG4 9NH (UK)

[d] Dr. Igor V. Sazanovich

Central Laser Facility, Research Complex at Harwell, Science and Technology Facilities Council, Harwell Campus, Didcot OX11 OQX, UK

[e] Dr. I. Lezcano-González, Prof. A. M. Beale Research Complex at Harwell, Rutherford Appleton Laboratory, Harwell Campus, Didcot, OX11 OFA (UK)

Supporting information for this article is given via a link at the end of the document.((Please delete this text if not appropriate)) as co-product. Mo-containing ZSM-5 zeolites are among the most studied catalysts for this reaction, with the pore dimensions of the MFI structure being key to provide shape selectivity to benzene (up to $80 \%$ ). ${ }^{[1-5]}$

It has been traditionally accepted that MDA over Mo/zeolites occurs via a bifunctional mechanism involving two different active sites $^{[2,3,6-9]}$ According to this mechanism, molybdenum species constitute the sites responsible for methane activation, forming $\mathrm{H}_{2}$ as well as $\mathrm{C}_{2} \mathrm{H}_{\mathrm{x}}$ and $\mathrm{C}_{3} \mathrm{H}_{\mathrm{x}}$ intermediates, which subsequently transform into aromatic products over the zeolite Brønsted acid sites (BAS) associated to framework $\mathrm{Al}^{3+}$. This mechanism was proposed on the basis of several activity studies carried out on Mo-based catalysts prepared using either non zeolitic supports such as $\mathrm{SiO}_{2}$ and $\mathrm{TiO}_{2}{ }^{[10]}$ - or $\mathrm{Cs}$, $\mathrm{Ca}$ or Na-exchanged zeolites, with no remaining BAS. While these materials showed low or no selectivity to aromatics, ${ }^{[11,12]}$ acidic zeolites led to 100-300 times more benzene yield. ${ }^{[13]}$ Furthermore, $\mathrm{Mo}_{2} \mathrm{C}$ and $\mathrm{H}-\mathrm{ZSM}-5$ alone were also reported to be poorly active. ${ }^{[5]}$

In line with these findings, it has been reported that $\mathrm{C}_{2} \mathrm{H}_{4}$ conversion on H-ZSM-5 zeolite led to a similar aromatics distribution than that obtained for $\mathrm{CH}_{4}$ on $\mathrm{Mo} / \mathrm{H}-\mathrm{ZSM}-5,{ }^{[14]}$ whereas Marczewski et al. obtained a direct correlation between the amount of framework $\mathrm{Al}$ and aromatic production, ${ }^{[15]}$ further supporting the idea that the aromatisation step occurs entirely on the Brønsted acid sites of the zeolite. In contrast, titration experiments performed by Tessonier et al. for the quantification of BAS after Mo exchange, revealed that regardless of the amount of BAS left, the catalysts had comparable yield to aromatics. ${ }^{[16]}$ The authors proposed that the enhanced activity in low Si/Al zeolites was mainly due to a better dispersion of Mo, leading to the formation of highly active isolated Mo species, and that a very few acid sites must be enough to perform the aromatisation of the ethylene intermediates. Interestingly, if the presence of BAS is necessary to produce aromatics from light hydrocarbons as postulated, their absence may allow for a catalyst that is selective to methane coupling products such as ethylene and ethane.

Nonetheless, an alternative monofunctional mechanism has been suggested on the basis that methane aromatisation can occur in the absence of BAS. Although with low conversion and selectivities, aromatisation on $\mathrm{MoO}_{3} / \mathrm{SiO}_{2}$ has been previously reported. ${ }^{[17]}$ More recently, Guo et al. synthesised a novel $\mathrm{Fe} @ \mathrm{SiO}_{2}$ catalyst, wherein isolated iron atoms were embedded and stabilised in a matrix of amorphous $\mathrm{SiO}_{2}{ }^{[18]}$ The authors showed MDA activity and high yields to benzene at $1000^{\circ} \mathrm{C}$. In agreement, catalytic data reported by Kosinov et al. for Mocontaining Silicalite-1, the pure siliceous analogue of H-ZSM-5 zeolite, evidenced the formation of aromatics over this catalyst 
material, leading to the proposal that Brønsted acid sites may not be essential for the aromatisation of methane. ${ }^{[19]}$ The same group has recently highlighted the involvement of confined carbon in the reaction mechanism instead. ${ }^{[20,21]}$

Our previous synchrotron-based operando studies on Mo/H-ZSM5 evidenced the relevance of Mo speciation in MDA product distribution. X-ray emission showed the selectivity to different hydrocarbon products to be dependent on Mo structure (i.e. partially carburised species were observed during the induction period when light hydrocarbons were produced, whereas fully carburised sites were selective to aromatics). ${ }^{[22]} \mathrm{X}$-ray absorption and diffraction experiments allowed to correlate the Mo species evolution with catalysts deactivation, a major handicap for the commercialisation of MDA route. ${ }^{[23]}$ This work showed that as a result of complete carburisation, Mo detaches from the zeolite; the subsequent Mo migration from the pores and loss of shape selectivity leads to the formation of carbon deposits on the zeolite outer surface. Accumulation of these deposits block the access of reactants to the active sites resulting in catalyst deactivation. ${ }^{[23]}$

From the works discussed above it is clear that metal ions such as Mo have a major role in the aromatisation stage than what has been traditionally postulated in the bifunctional mechanism. To date, the extensive research carried out to determine the influence of catalyst support on activity does not include a thorough characterisation to account for differences in metal speciation. Therefore, the aim of this research is to compare the of Mo-containing MFI zeolites in order shed more light onto the role of Mo speciation, framework $\mathrm{Al}^{3+}$ and BAS. This is carried out by studying the structure and catalytic activity of Mo/Silicalite- 1 with no Al, in comparison with the widely studied Mo/H-ZSM-5 with a silicon to aluminium ratio of 15 and comparable Mo loadings of around $4 \mathrm{wt}$. \%. Notably, the study of a pure siliceous zeolite material containing highly dispersed Mo-oxo species (vide infra) allows us to disentangle the influence of Mo structure and zeolite acidity on the catalytic behaviour largely debated over the past decades. The nature of initial Mo-oxo species is investigated in detail by X-ray absorption spectroscopy (XAS) and density functional theory (DFT), while the physicochemical properties of reacted catalysts are evaluated by characterisation of samples in the first few hours of the MDA reaction.

\section{Results and Discussion}

\section{Study of Mo speciation within Mo-MFI structures XAS during in situ calcination}

The Mo K-edge XAS data collected during calcination of the asprepared $\mathrm{Mo} /$ Silicalite-1 is shown in Figure 1. The X-ray absorption near edge structure (XANES) spectra (Figure1a) present a pre-edge peak around $20005 \mathrm{eV}$ (dipole-forbidden 1s $\rightarrow 4 d$ electronic transition) and a rising absorption edge at 20015 $\mathrm{eV}$ (dipole-allowed $1 \mathrm{~s} \rightarrow 5 \mathrm{p}$ transition). The spectra do not change significantly up to $600{ }^{\circ} \mathrm{C}$ indicating that the local structure of the $\mathrm{MoO}_{3}$ precursor (comprising interconnected $\mathrm{MoO}_{6}$ octahedra) does not change significantly. Above $600{ }^{\circ} \mathrm{C}$, the pre-edge intensity increases, indicating changes in the symmetry around molybdenum from octahedral to tetrahedral. ${ }^{[2]}$ In addition, the post-edge region (> $20030 \mathrm{eV}$ ) above $600{ }^{\circ} \mathrm{C}$ loses its features resulting in a broad peak, suggesting loss of long-range order and dispersion into isolated Mo-oxo species attached to the microporous framework. ${ }^{[25]}$
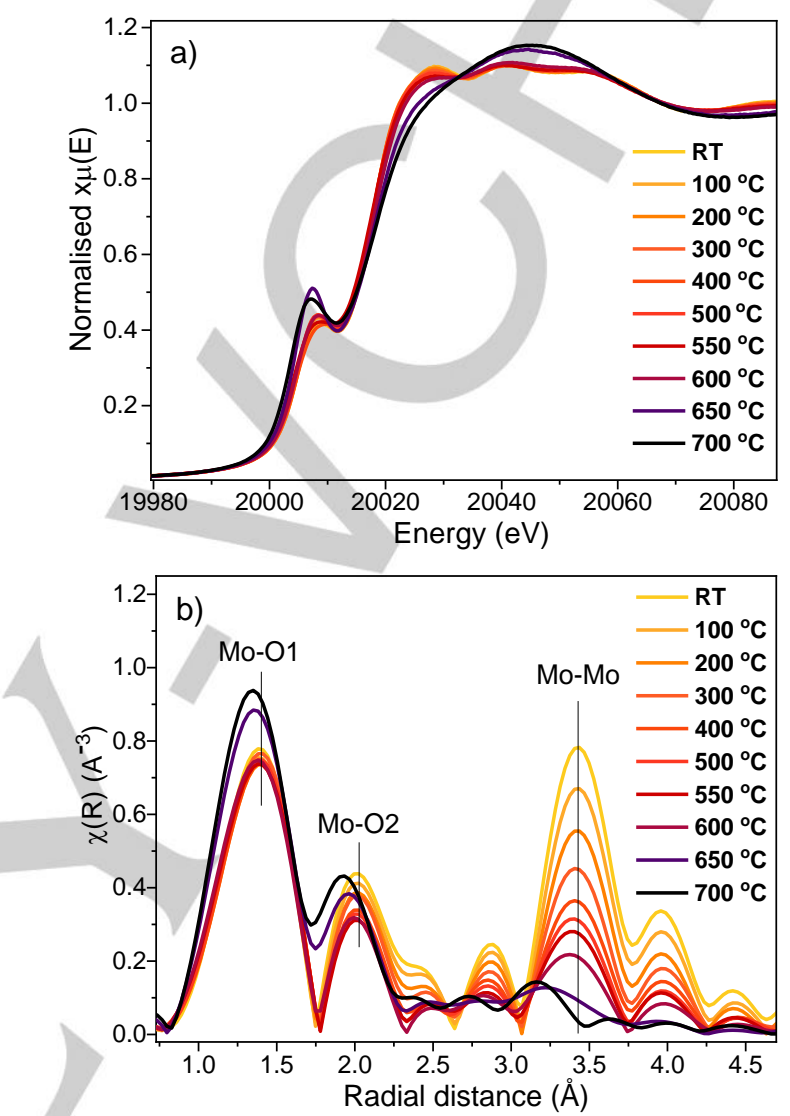

Figure 1. Mo K-edge XAS data collected during in situ calcination of Mo/Silicalite-1 $\left(20 \% \mathrm{O}_{2}\right.$ in $\left.\mathrm{He}, 700^{\circ} \mathrm{C}, 5^{\circ} \mathrm{C} / \mathrm{min}\right)$ : a) XANES spectra, b) FTEXAFS (no phase corrected) with vertical lines indicating the peaks assigned to $\mathrm{Mo}-\mathrm{O}$ and $\mathrm{Mo}-\mathrm{Mo}$ scattering paths in the $\mathrm{MoO}_{3}$ precursor.

The Fourier transforms of the X-ray absorption fine structure (FTEXAFS) are shown in Figure 1b. At low temperatures the spectra present features typical of $\mathrm{MoO}_{3}$, which contains distorted octahedral $\mathrm{MoO}_{6}$ units. ${ }^{[25,26]}$ The scattering from near neighbour $O$ results in two resolved peaks in the FT-EXAFS, with maxima around $1.3 \AA$ (labelled as Mo-O1) and $2.0 \AA$ (Mo-O2). The third peak observed, between 3 and $4 \AA$, arises from scattering from neighbouring Mo atoms in agreement with reported Mo-Mo bond distance of c.a. $3.5 \AA_{.}^{[27]}$ During calcination, a gradual decrease in the peak intensity is observed below $600^{\circ} \mathrm{C}$, this decrease is more pronounced for atoms at longer radial distances and can be attributed to an increasing thermal disorder which leads to the damping of the EXAFS oscillations. In line with the XANES results, there are no shifts in the position of the peaks, suggesting that Mo local structure is not significantly altered in this temperature range. Above $600{ }^{\circ} \mathrm{C}$ however, sudden changes in the FT-EXAFS indicate the formation of isolated Mo-oxo species attached to the 
Silicalite-1 framework. The peak at radial distances > $3.0 \AA$ disappear, evidencing loss of Mo-Mo scattering; the peak with maxima around $2.0 \AA$ moves to shorter bond distances, probably corresponding to $\mathrm{O}$ atoms bridging to the zeolite, and the peak at lowest radial distances red-shifts, consistent with the formation of short terminal $\mathrm{Mo}=\mathrm{O}$ double bonds. ${ }^{[23]}$

Unlike Silicalite-1, H-ZSM-5 contains framework Al atoms, which provide ion exchange capacity and strong anchoring points for the Mo-oxo species. Characterisation of the acidic properties of the materials here used ( $\mathrm{NH}_{3}$-TPD and FTIR) can be found in Figure S1 in the ESI. In spite of the absence of framework Al, the observed Mo structure evolution into tetrahedral-like Mo-oxo species on Silicalite-1 is analogous to previous reports on acidic $\mathrm{Mo} / \mathrm{H}-\mathrm{ZSM}-5 .{ }^{[22,23,25]}$ For comparison, Figure S2 in the ESI presents the X-ray absorption spectra collected for Mo/H-ZSM-5 during in situ calcination under identical experimental conditions. In agreement with the XAFS data, no $\mathrm{MoO}_{3}$ crystallites were detected by XRD in the calcined Mo/Silicalite-1 (see Figure S3 in the $\mathrm{ESI}$ ), indicating that $\mathrm{Mo}$ is well dispersed after calcination. Furthermore, a decrease in the micropore volume (14\%) was also observed upon calcination (Table 2), supporting the migration of Mo into Silicalite-1 pores. By FTIR a decrease in intensity of the bands corresponding to the silanol groups in Silicalite- 1 is seen upon calcination of the physical mixture (Figure S1b), suggesting that metal dispersion may partially occur via interaction of Mo with such groups.

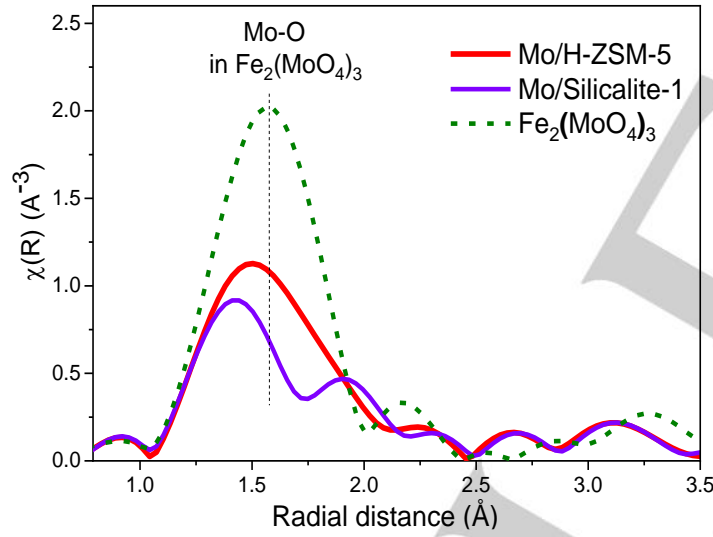

Figure 2. Mo K-edge FT-EXAFS for Mo/Silicalite-1 and Mo/H-ZSM-5 samples at room temperature after in situ calcination together with FT-EXAFS for $\mathrm{Fe}_{2}\left(\mathrm{MoO}_{4}\right)_{3}$ reference with tetrahedral $\mathrm{MoO}_{4}$ units. Vertical dashed line marks the radial distance for the maxima of the $\mathrm{Fe}_{2}\left(\mathrm{MoO}_{4}\right)_{3}$.

The room temperature FT-EXAFS for calcined Mo/Silicalite-1 and Mo/H-ZSM-5 catalysts are compared in Figure 2. The plot also includes the spectrum of a $\mathrm{Fe}_{2}\left(\mathrm{MoO}_{4}\right)_{3}$ reference, containing tetrahedral $\mathrm{MoO}_{4}$ units with an average Mo-O distance of $\sim 1.75$ A. Compared to $\mathrm{Fe}_{2}\left(\mathrm{MoO}_{4}\right)_{3}, \mathrm{Mo} /$ zeolites seem to present a component at lower radial distances, which is consistent with the presence of short $\mathrm{Mo}=\mathrm{O}$ bonds. ${ }^{[23]}$ Interestingly, the two Mo-O distances (i.e. terminal $\mathrm{Mo}=\mathrm{O}$ and bridging $\mathrm{Mo}-\mathrm{O}$ bonds to the zeolite framework) in the calcined Mo/Silicalite-1 result in two well resolved peaks, while in contrast, Mo/H-ZSM- 5 exhibits a single broad peak. This could be explained by a different degree of interaction between Mo and framework oxygen atoms in both zeolites. Consistent with the absence of framework Al, the interaction of Mo with the pure siliceous Silicalite-1 framework is weaker, resulting in longer Mo-O distances for the bridging oxygen atoms and allowing for better resolution of $\mathrm{Mo}=\mathrm{O}$ and $\mathrm{Mo}$ O scattering peaks in the FT-EXAFS.

In order to refine the two bond distances, a first shell fit of the EXAFS spectra collected at room temperature after the in situ calcination was performed. The best fits were obtained by setting the coordination number 2 for both short and long molybdenumoxygen bond distances typical of a $(\mathrm{O}=)_{2} \mathrm{Mo}(-\mathrm{O}-\mathrm{Si})_{2}$ species. Table 1 presents the parameters refined for Mo/Silicalite- 1 and $\mathrm{Mo} / \mathrm{H}-\mathrm{ZSM}-5$, the experimental and simulated spectra are plotted together in Figure $\mathrm{S} 4$ in the ESI. The results suggest similar $\mathrm{Mo}=\mathrm{O}$ bond distances of $1.69 \AA$ for both samples while the Mo-O distance is considerably longer on the pure siliceous zeolite (i.e. $2.31 \AA$ in Mo/Silicalite-1 vs $1.80 \AA$ in $\mathrm{Mo} / \mathrm{H}-\mathrm{ZSM}-5)$.

Table 1. EXAFS fitting parameters for Mo/Silicalite-1 and Mo/H-ZSM- 5 spectra acquired at RT after calcination: $\mathrm{So}^{2}=0.91$, Fit Range: $3<\mathrm{k}<12,1$ $<\mathrm{R}<3$. Where $\mathrm{CN}=$ coordination number, $\mathrm{R}=$ bond length of the AbsorberScatterer, $\sigma^{2}=$ Mean squared disorder term (sometimes referred to as the Debye Waller factor), $E_{o}=$ Energy shift, $R_{\text {Factor }}=A$ statistic of the fit, which is a way of visualising how the misfit is distributed over the fitting range.

\begin{tabular}{|c|c|c|c|c|c|c|}
\hline Sample & Schell & CN & $R(\AA)$ & $\sigma^{2}\left(\AA^{2}\right)$ & $E_{0}$ & $\begin{array}{c}\mathbf{R}_{\text {Factor }} \\
(\%)\end{array}$ \\
\hline \multirow{2}{*}{$\begin{array}{c}\mathrm{Mo} / \\
\text { Silicalite-1 }\end{array}$} & & 2 & & $\begin{array}{c}0.0046 \\
(+/-0.0012)\end{array}$ & \multirow{2}{*}{$\begin{array}{c}11.93 \\
(+/-2.03)\end{array}$} & \multirow{2}{*}{3.5} \\
\hline & Mo-O & 2 & $\begin{array}{c}2.31 \\
(+/-0.03)\end{array}$ & $\begin{array}{c}0.0079 \\
(+/-0.0030)\end{array}$ & & \\
\hline \multirow{2}{*}{$\begin{array}{c}\mathrm{Mo} / \\
\mathrm{H}-\mathrm{ZSM}-5\end{array}$} & $\mathrm{Mo}=\mathrm{O}$ & 2 & 1.69 & $\begin{array}{c}0.0059 \\
(+/-0.0043)\end{array}$ & \multirow{2}{*}{$\begin{array}{c}-0.15 \\
(+/-2.61)\end{array}$} & \multirow{2}{*}{3.2} \\
\hline & Mo-O & 2 & $\begin{array}{c}1.80 \\
(+/-0.04)\end{array}$ & $\begin{array}{c}0.0041 \\
(+/-0.0016)\end{array}$ & & \\
\hline
\end{tabular}

\section{Density functional theory}

In order to verify these observations, DFT calculations were performed, allowing to gain further insight into the interaction of Mo with Silicalite-1 support. These were concerned with the optimisation of isolated di-coordinated Mo-oxo structures with tetrahedral geometry, as suggested by the above $\mathrm{X}$-ray absorption results. The fully geometry optimised structures, shown in Figure 3, comprise pseudo-tetrahedral $\left[\mathrm{MoO}_{2}\right]^{2+}$ sites attached to the zeolite walls through two $\mathrm{Mo}-\mathrm{O}_{\mathrm{F}}$ bonds to oxygen atoms on oxygens adjacent to the T5 site; they also contain two terminal $\mathrm{Mo}=\mathrm{O}$ bonds. In the case of Mo/Silicalite- 1 (Figure 3a) the bond lengths obtained are $1.73 \AA$ and $2.33 \AA$ for $\mathrm{Mo}=\mathrm{O}$ and Mo- $\mathrm{O}_{F}$ respectively. These values are comparable to those refined by EXAFS ( $1.69 \AA$ and $2.31 \AA$ ). Note that the Mo-OF length could be considered too long to be a real bond; nonetheless, the Mulliken charges on the two framework oxygens 'bonded' to Mo are more negative than charges on other framework oxygens, (0.55 compared to a mean charge of -0.45 for the remaining framework oxygens). This indicates that an electrostatic 
interaction exists, and that charge transfer occurs between framework oxygens and Mo. a)

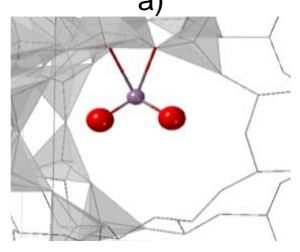

$\mathrm{Mo}=\mathrm{O}: 1.73 \AA$ Mo-OF: $2.33 \AA$ b)

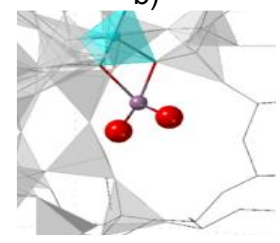

Mo-OF: $1.80 \AA$
$\mathrm{Mo}=\mathrm{O}: 1.73 \AA$ c)

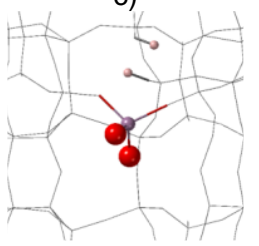

$\mathrm{Mo}=\mathrm{O}: 1.69 \AA$

Mo-OF: $1.90 \AA$

Mo-OF: $1.88 \AA$ d)

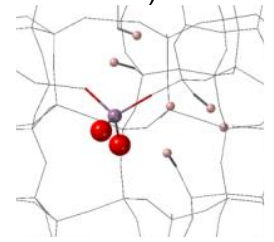

$\mathrm{Mo}=0: 1.70 \AA$

Mo-OF: $1.90 \AA$

Mo-OF: $1.88 \AA$ e)

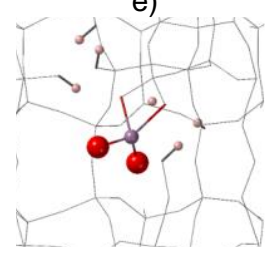

$\mathrm{Mo}=\mathrm{O}: 1.70 \AA$ Mo-OF: $1.97 \AA$ Mo-OF: $2.08 \AA$
Figure 3. The fully geometry optimised form of the Mo-oxo species bound to Silicalite-1 (a) and H-ZSM-5 (b). The bonding to Silicalite-1 through silanol defects is modelled across the nests (c), vicinal (d) and non-vicinal silanol defects $(\mathrm{e})$. In all structures [MoO2]2+ contains two terminal $\mathrm{Mo}=\mathrm{O}$ bonds and is di-coordinated by two short Mo-OF bonds. The framework is shown as stick bonds, Mo is represented in purple, oxygen in red and hydrogen in pink.

For Mo/H-ZSM-5 (Figure $3 \mathrm{~b}$ ), while the $\mathrm{Mo}=\mathrm{O}$ bond distance is equivalent to the Mo/Silicalite-1, the Mo- $\mathrm{O}_{\mathrm{F}}$ bond obtained is significantly shorter with a value of $1.8 \AA$. This value is comparable to our EXAFS results in Table 1 as well as previous theoretical calculations on Mo/H-ZSM-5. ${ }^{[28]}$ The shorter distance compared to Silicalite- 1 is presumably due to strong interactions between the Mo-oxo species and the aluminosilicate framework. By FTIR a range of silanol defect groups were found to exist in the Silicalite- 1 sample that may serve as anchoring point of Mooxo species. These defects include vicinal, geminal and large number of silanol nests (see Figure S2 for the assignments). Previous DFT studies have shown variations in the stability Mooxo species anchored through different silanol defects of an amorphous silica support. ${ }^{[29]}$ To evaluate the effect of silanol defects on the binding of the initial Mo-oxo to the walls of the zeolite framework, a range of silanol-containing Mo/Silicalite-1 structures were examined. As geminal sites have been reported to be highly unstable due to their rigidity, ${ }^{[29]}$ only vicinal and nonvicinal sites are considered.

As indicated in the experimental section, the presence of silanol nests were simulated through the removal of a single Si atom from the T5 sites. The four dangling $\mathrm{Si}-\mathrm{O}$ bonds generated by the introduction of the vacant site were satisfied by the presence of hydroxyls. $\left[\mathrm{MoO}_{2}\right]^{2+}$ was then di-coordinated across the now vacant T5 site, with the removal of two protons, simulating binding across two terminal silanol defects via a condensation reaction. The fully geometry optimised form of this structure is shown in Figure $3 \mathrm{c}$. This structure contains equivalent $\mathrm{Mo}=\mathrm{O}$ bond lengths of $1.69 \AA$; $\mathrm{Mo}^{-} \mathrm{O}_{\mathrm{F}}$ bond lengths however are shorter than those reported for the Mo-oxo species supported on silanol-free Silicalite-1 (in Figure $3 a$ ) with one bond slightly longer than the other, $\mathrm{Mo}-\mathrm{O}_{\mathrm{F}}=1.90 \AA$ and $1.88 \AA$.

The fully optimised structures of $\left[\mathrm{MoO}_{2}\right]^{2+}$ bound across vicinal and non-vicinal silanol groups are shown in Figure $3 \mathrm{~d}$ and $3 \mathrm{e}$ respectively. In these structures, Si has been removed from the T5 and T9 sites and the resulting dangling bonds are satisfied by hydroxyls, simulating the presence of two silanol nests per MFI unit cell. The calculations suggest that bonding to vicinal $\mathrm{OHs}$ is more stable than non-vicinal by $52 \mathrm{~kJ} \mathrm{~mol}^{-1}$, contrary to the work by Guesmi et al.[29] The bond lengths in these structures are $\mathrm{Mo}=\mathrm{O}=1.70 \AA$ and $\mathrm{Mo}-\mathrm{O}_{\mathrm{F}}=1.90 \AA$ and $1.88 \AA$ for binding across the vicinal site and $\mathrm{Mo}=\mathrm{O}=1.70 \AA$ and $\mathrm{Mo}-\mathrm{O}_{\mathrm{F}}=1.97 \AA$ and 2.08 $\AA$. Mulliken population analysis suggests that Mo is interacting with both framework oxygens, hence it appears that binding at vicinal sites is preferred as a consequence of stronger, more equal coordination to the framework. The DFT calculations for Mo attached to Silicalite-1 through silanols result in significantly shorter Mo-OF bond lengths ( 1.88 to $2.08 \AA$ ) compared to the ones obtained by EXAFS fitting ( $2.31 \AA$ ) $)$. In contrast, the model with no silanols in the structure is closer $\left(\mathrm{Mo}-\mathrm{O}_{\mathrm{F}}=2.33 \AA\right.$ ) to the fitted values. This suggests that the Mo-oxo species are not bound exclusively across vacancy sites in the Silicalite- 1 framework and that interaction and charge transfer occurs between framework oxygen atoms and Mo.

\section{Methane dehydroaromatisation Catalytic activity}

To compare the performance of Mo/H-ZSM-5 and Mo/Silicalite-1, MDA reactions were carried out for a period of $10 \mathrm{~h}$, with the outlet gas composition measured by MS. The data corresponding to the main reaction products (i.e. $\mathrm{H}_{2}, \mathrm{C}_{2} \mathrm{H}_{\mathrm{x}}$ and $\mathrm{C}_{6} \mathrm{H}_{6}$ ) are presented in Figure 4. Both catalysts exhibit an induction period during the first minutes of reaction where $\mathrm{H}_{2}$ formation is seen but no hydrocarbon production is detected (data from earlier reaction times are shown in Figures $4 \mathrm{a}$ and $4 \mathrm{~b}$ ). This induction period is coincident with the evolution of $\mathrm{CO}, \mathrm{CO}_{2}$ and $\mathrm{H}_{2} \mathrm{O}$ (see Figure S5 for the MS trends of combustion products) and it is accepted that during this stage tetrahedral Mo-oxo species undergo reduction and carburisation leading to the formation of active species for dehydroaromatisation. After the initial induction period, the aromatisation stage was seen to commence for both catalysts evidenced by the evolution of $\mathrm{C}_{6} \mathrm{H}_{6}$, together with light hydrocarbons and $\mathrm{H}_{2}$. In agreement with Kosinov et al., ${ }^{[19]}$ the observed formation of $\mathrm{C}_{6} \mathrm{H}_{6}$ on $\mathrm{Mo} /$ Silicalite-1 suggests that BAS are not required for aromatisation, pointing out to this being also an intrinsic property of molybdenum carbide species. ${ }^{[5]}$

A close analysis of the MS data reveals differences in MDA performance of both catalysts. Interestingly, a shorter induction period is observed for Mo/Silicalite-1 (6.0 min) compared with the Mo/H-ZSM-5 (8.5 min) which suggests a faster carburisation of initial Mo-oxo species on the pure Si zeolite. Regarding the aromatisation stage, data over the $10 \mathrm{~h}$ of reaction (Figures $4 \mathrm{c}$ 
and $4 \mathrm{~d}$ ) show that $\mathrm{C}_{6} \mathrm{H}_{6}$ and $\mathrm{H}_{2}$ gradually decreased for $\mathrm{Mo} / \mathrm{H}$ ZSM-5 indicating a steady catalyst deactivation. For Mo/Silicalite1 however, $\mathrm{C}_{6} \mathrm{H}_{6}$ and $\mathrm{H}_{2}$ were seen to steeply decrease within the first $\sim 3 \mathrm{~h}$ of reaction, evidencing a significantly faster deactivation. In addition, the TGA analysis (Table 2) performed for catalysts reacted for different times revealed increased amounts of carbon deposits on Mo/Silicalite-1.

These activity differences can be explained by the degree of interaction of Mo with the zeolite framework as discussed in the EXAFS and DFT studies above. In the Mo evolution mechanism proposed from our previous operando studies, during the induction period the Mo-oxo species present after calcination are fully carburised; this occurs by the consecutive replacement of terminal and bridging $\mathrm{O}$ atoms by $\mathrm{C}^{[22,23]}$ The weaker interaction of Mo with Silicalite- 1 compared with H-ZSM- 5 would potentially facilitate the carburisation of bridging $O$ therefore shortening the induction period. Such weaker interaction would also lead to a faster sintering of Mo species and their migration to the outer surface under reaction conditions. In line with the deactivation mechanism previously proposed by our group, ${ }^{[23]}$ the shape selectivity to aromatics provided by the MFI pore structure is lost as a consequence of this migration, favouring the formation of large carbonaceous deposits in the zeolite outer surface. Hence,
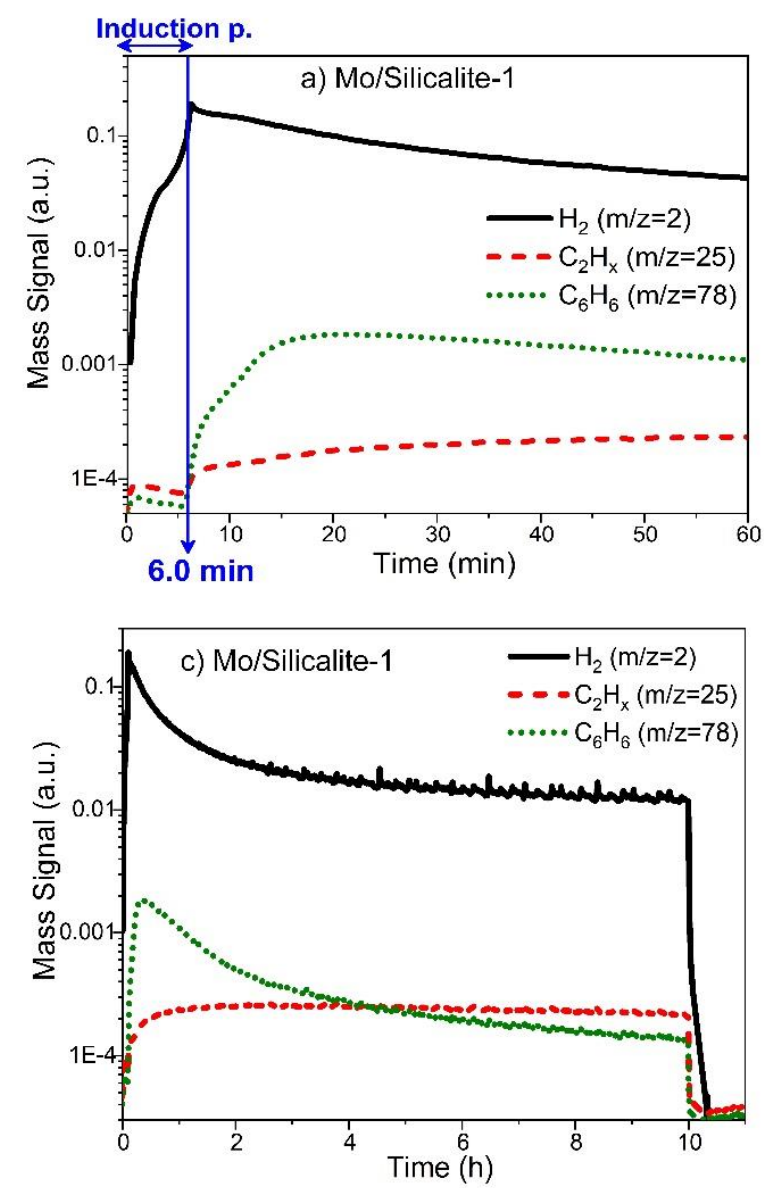

a faster sintering of the active species in Mo/Silicalite-1 would explain the increased formation of carbon deposits in this catalyst - as observed by TGA, and thereby the faster deactivation.

\section{Post reaction characterisation}

In order to gain insight into the fast deactivation of Mo/Silicalite-1, the reacted catalysts (i.e. after $7 \mathrm{~min}, 90 \mathrm{~min}$ and $10 \mathrm{~h}$ of reaction) were further characterised.

Table 2 displays the textural properties and the carbon content measured by TGA. Note that the Mo content (determined by ICP for the calcined samples) is similar for both catalysts. As compared to the parent zeolites, the micropore volume of the calcined Mo-containing catalysts was seen to significantly decrease; this decrease is similar for Mo/Silicalite-1 (14\% decrease) and Mo/H-ZSM-5 (16\% decrease) suggesting a comparable Mo dispersion. As discussed in the XAFS section above, the drop in micropore volume is probably driven by the migration of Mo into the zeolite pores during calcination to form Mo-oxo species. From $7 \mathrm{~min}$ to $10 \mathrm{~h}$ of reaction, the micropore volume was also seen to decrease as a result of carbon deposition. The increase in the amount of deposited carbon is clearly evidenced by TGA, responsible for the gradual catalyst deactivation observed in Figure 4. The derivatives of the TGA
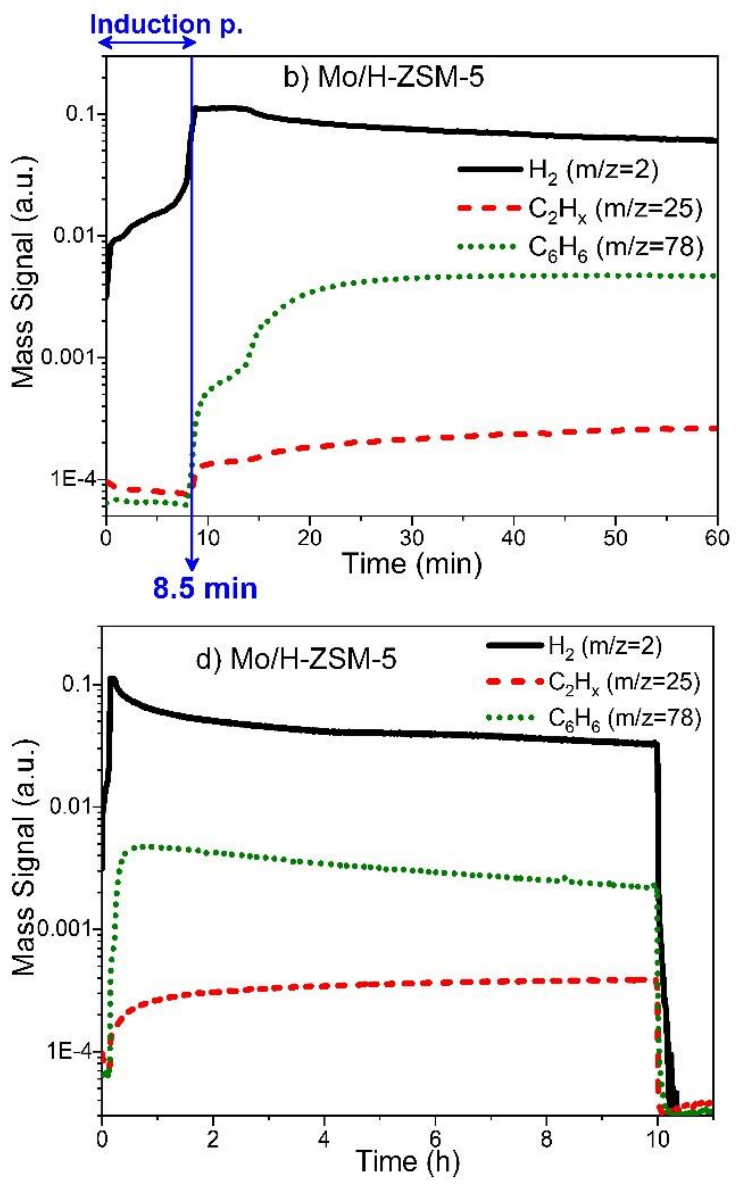

Figure 4. MS profiles of reaction products under methane dehydroaromatisation reaction $\left(50 \% \mathrm{CH}_{4} / \mathrm{Ar}, 1500 \mathrm{~h}^{-1}\right.$, $700{ }^{\circ} \mathrm{C}$ ). First 60 min for Mo/Silicalite-1 (a) and Mo/H-ZSM-5 (b) with vertical lines marking the end of the induction period. $10 \mathrm{~h}$ reaction data for Mo/Silicalite-1 (c) and Mo/H-ZSM-5 (d). 
curves at 7, $25 \mathrm{~min}$ and $10 \mathrm{~h}$ of reaction (Figure S6 in the ESI) also exhibit a gradual increase of peak intensity and the combustion temperature with reaction time, in line with increased carbon deposition as the reaction advances. As shown in Table 2 the amount of carbon deposited on Mo/Silicalite-1 was always higher than for Mo/H-ZSM-5 consistent with the faster deactivation observed when the pure siliceous zeolite is used as the support.

Table 2. $\mathrm{N}_{2}$ physisorption results and carbon content for Mo/MFI catalysts after different MDA reaction times.

\begin{tabular}{ccccc}
\hline Sample & $\begin{array}{c}\text { Mo } \\
\text { (wt. \%) }\end{array}$ & $\begin{array}{c}\text { TGA-Carbon } \\
\mathbf{3 5 0 - 6 0 0} \mathbf{C} \\
\text { (wt. \%) }\end{array}$ & $\begin{array}{c}\mathbf{S}_{\mathrm{BET}} \\
\left(\mathbf{m}^{2} / \mathbf{g}\right)\end{array}$ & $\begin{array}{c}\mathbf{V}_{\text {micr }} \\
\left(\mathbf{c m}^{3} \mathbf{g}\right)\end{array}$ \\
\hline H-ZSM-5 & $/$ & $/$ & 412 & 0.15 \\
Mo/H-ZSM-5 calc. & 3.80 & $/$ & 344 & 0.12 \\
Mo/H-ZSM-5(7min) & $/$ & 0.4 & 351 & 0.12 \\
Mo/H-ZSM-5(90min) & $/$ & 3.0 & 326 & 0.11 \\
Mo/H-ZSM-5(10h) & $/$ & 6.3 & 280 & 0.09 \\
\hline Silicalite-1 & $/$ & $/$ & 452 & 0.17 \\
Mo/Silicalite-1 calc. & 3.62 & $/$ & 389 & 0.14 \\
Mo/Silicalite-1(7min) & $/$ & 0.5 & 409 & 0.14 \\
\hline $\begin{array}{c}\text { Mo/Silicalite-1(90min) } \\
\text { Mo/Silicalite-1(10h) }\end{array}$ & $/$ & 5.4 & 333 & 0.12 \\
\hline
\end{tabular}

In order to gain knowledge on the nature of carbon deposits formed during reaction, Raman spectra was acquired for the catalysts reacted for 90 min. Figure 5 shows the first order Raman bands for Mo/Silicalite-1 and Mo/H-ZSM-5, which present two distinct bands typical for carbon compounds. The band around $1360 \mathrm{~cm}^{-1}$ is denoted as D1 (disordered) band and it is ascribed to in-plane breathing vibrations of $\mathrm{sp}^{2}$-bonded carbon (rings). The D1 band is usually attributed to amorphous carbon, carbon nanoparticles or defects in graphitic-type deposits. ${ }^{[30]}$ The second band is known as the $\mathrm{G}$ (graphitic) band, it usually appears at $1580 \mathrm{~cm}^{-1}$ and corresponds to in-plane stretching vibrations of pairs of $\mathrm{sp}^{2} \mathrm{C}$ atoms. This band is observed in graphitic-type carbon as a result of lattice vibrations. ${ }^{[30-32]}$ In both catalysts these bands are shifted to higher wavenumbers $\left(1611 \mathrm{~cm}^{-1}\right)$. This shift has been reported to be due to a contribution from a second D2 band $\left(1620 \mathrm{~cm}^{-1}\right)$ attributed to edges of graphitic crystallites. ${ }^{[32,33]}$ Thus, the observed shift suggests the presence of very small carbon crystallites with large surface/bulk ratio and therefore a high number of edges. ${ }^{[32,34]}$ A weak shoulder can be also observed at $1200 \mathrm{~cm}^{-1}$, this Raman shift has been named as a D4 band and it is ascribed to the stretching vibrations of sp2-sp3 C$\mathrm{C}$ bonds in conjugated aliphatic species. ${ }^{[35]}$ The ratio of D1 and $G(D 2)$ bands intensities gives insight regarding the degree of order in the carbon structure; ${ }^{[30,32]}$ increasing $I(D 1) / I(G)$ indicates increasing structural disorder. The higher $D 1 / G$ value for Mo/Silicalite-1 (0.61) than for Mo/H-ZSM-5 (0.52) indicates the carbon deposited on the catalyst with no framework $\mathrm{Al}$ is more amorphous in nature. Hence, Raman studies confirm the formation of significant amounts of disordered graphitic carbon or small graphite crystallites in the spent samples, with lower degree of crystallinity for Mo/Silicalite-1. From our Raman or TGA data it is difficult to discern between carbon deposits located inside the zeolite channels or on the outer surface. Our previous PXRD studies on Mo/H-ZSM-5 however, suggests that most of the carbon is located in the external surface of the zeolite crystals. ${ }^{[23]}$

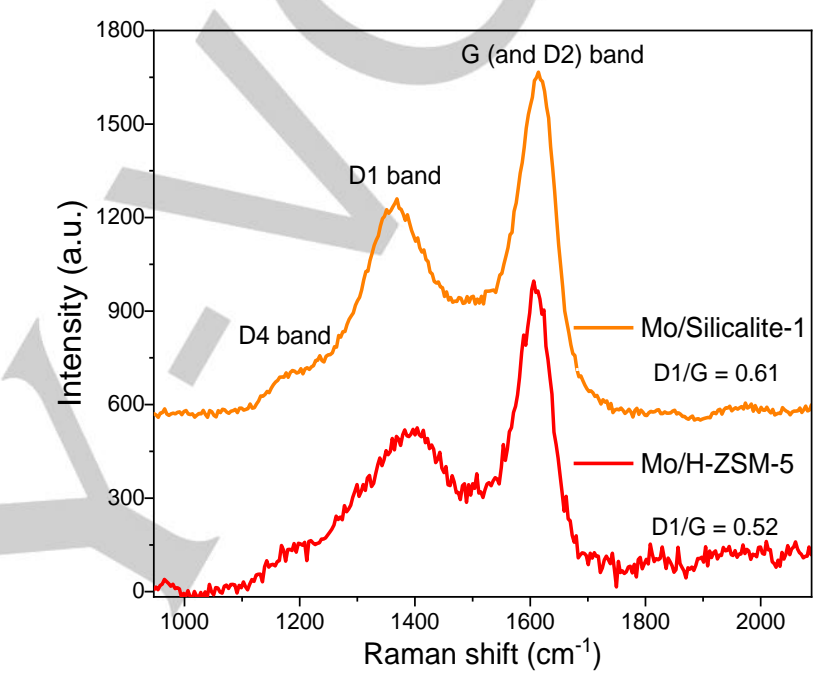

Figure 5. Raman spectra for Mo/Silicalite-1 and Mo/H-ZSM-5 reacted for $90 \mathrm{~min}$ $\left(50 \% \mathrm{CH}_{4} / \mathrm{N}_{2}, 700{ }^{\circ} \mathrm{C}, 1500 \mathrm{~h}^{-1}\right)$.

Microscopy studies (TEM and SEM) were also carried out for reacted catalysts in order to evaluate the Mo sintering process during MDA. High resolution backscattered electron images for Mo/Silicalite-1 reacted for $7 \mathrm{~min}, 90 \mathrm{~min}$ and $10 \mathrm{~h}$ are shown in Figure 6 and illustrate the sintering process of Mo species under reaction conditions. The images contain Silicalite- 1 crystals of around $200 \mathrm{~nm}$, whereas the observed bright spots are, based on signal intensity, due to molybdenum carbide. ${ }^{[23]}$ Note that this analysis was done using a low accelerating voltage of $1.6 \mathrm{eV}$; hence, the Mo distribution observed corresponds to the outermost surface of the zeolite crystals.

Very few bright spots are present after $7 \mathrm{~min}$ of reaction (Figure 6a) suggesting a low degree of molybdenum carbide sintering towards the zeolite surface at this stage of reaction. The $90 \mathrm{~min}$ reacted sample (Figure $6 \mathrm{~b}$ ) presents an increased number of molybdenum carbide particles whereas after $10 \mathrm{~h}$ (Figure $6 \mathrm{c}$ ), the number of these particles increases further such that all zeolite crystals possess sintered molybdenum carbide on the surface. A similar trend is also observed for $\mathrm{Mo} / \mathrm{H}-\mathrm{ZSM}-5$, in line with previous publications (see Figure $\mathrm{S} 7$ in the $\mathrm{ESI}$ for equivalent images in Mo/H-ZSM-5). ${ }^{[7,22]}$ 
a)

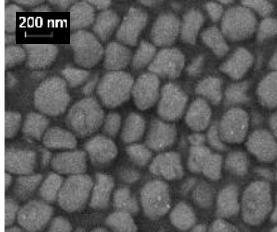

b)

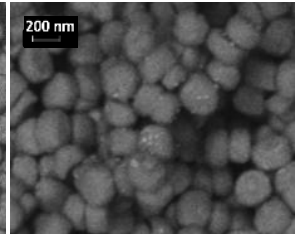

c)

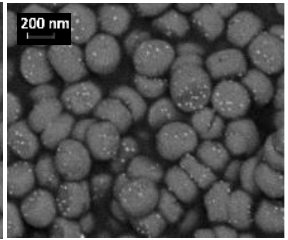

Figure 6. SEM-ESB (Energy Selected Backscattered) electron images (accelerating voltage $1.6 \mathrm{eV}$ ) for Mo/Silicalite-1 after $7 \mathrm{~min}(\mathrm{a}), 90 \mathrm{~min}(\mathrm{~b})$, and $10 \mathrm{~h}$ (c) of MDA reaction $\left(50 \% \mathrm{CH}_{4} / \mathrm{N}_{2}, 700{ }^{\circ} \mathrm{C}, 1500 \mathrm{~h}^{-1}\right)$.

TEM images were also taken at 90 min of MDA where the steep deactivation of Silicalite-1 is observed in contrast of more stable activity of Mo/H-ZSM-5. As shown in Figure 7 a Mo/Silicalite-1 presents large molybdenum carbide particles of around $15 \mathrm{~nm}$ diameter, while Mo/H-ZSM-5 (Figure 7c) exhibits significantly smaller particles (> $5 \mathrm{~nm}$ ). After $10 \mathrm{~h}$ of reaction extensive sintering was observed for both catalysts. As expected, the EDX maps (Figure $7 b$ and $7 d$ ) reveal Mo to be associated with $C$, consistent with the presence of molybdenum carbide particles. An even distribution of $\mathrm{Si}$ and $\mathrm{O}$ were found in the zeolite crystals, while the Al distribution in Mo/H-ZSM-5 presents brighter spots probably due to presence of extra framework aluminium or $\mathrm{Al}$ molybdate particles. Interestingly, in the $C$ elemental map of Mo/Silicalite-1, which contains a higher amount of $C$, a more intense carbon signal can be distinguished on the periphery of the Silicalite-1 particles (Figure 7b). This indicates a significant accumulation of carbon deposits on the outer surface of the zeolite.

a)

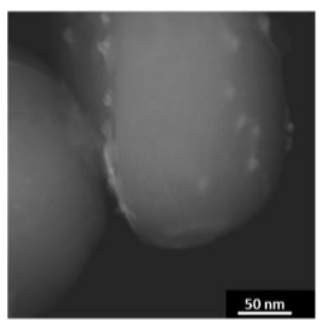

C)

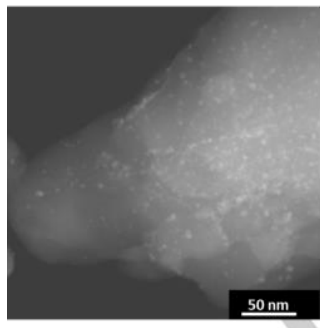

Figure 7. STEM-DF image for 90 min reacted $\left(50 \% \mathrm{CH}_{4} / \mathrm{N}_{2}, 700{ }^{\circ} \mathrm{C}, 1500 \mathrm{~h}-1\right)$ catalysts. Mo/Silicalite-1 (a) and Mo/H-ZSM-5 (c); and $10 \mathrm{~h}$ reacted STEM-DF with the corresponding EDX elemental maps for Mo/Silicalite-1 (b) and Mo/HZSM-5 (d).
These results are in agreement with the catalytic activity data and deactivation mechanism discussed in Figure 4. The weak interaction between initial Mo species and Silicalite- 1 observed by EXAFS and DFT is a key factor for the enhanced sintering of the Mo active species seen by TEM. The migration of Mo carbides to the outer zeolite surface leads to an increased carbon deposition on the zeolite periphery and thereby, a more rapid deactivation of Mo/Silicalite-1.

\section{Summary and Conclusions}

This study compares the properties of Mo/zeolites with MFI structure using zeolites with and without framework Al (H-ZSM-5 and Silicalite-1 respectively). The structural refinement of the initial Mo-oxo species by XAS and DFT, followed by MDA activity studies and characterisation of reacted catalysts bring new insights into the role of framework $\mathrm{Al}$ on the catalytic performance. XAS data collected during in situ calcination of Silicalite- 1 and $\mathrm{MoO}_{3}$ physical mixture suggest that upon calcination $\mathrm{MoO}_{3}$ migrates into zeolite pores, leading to the formation of tetrahedral Mo-oxo species. The structure of these species (i.e. with two terminal $\mathrm{Mo}=\mathrm{O}$ and two bridging $\mathrm{Mo}-\mathrm{O}$ groups attached to the zeolite framework) appears to be analogous to the ones previously reported for ion-exchanged $\mathrm{Mo} / \mathrm{H}-\mathrm{ZSM}-5$, with the BAS acting as anchoring sites for Mo. Longer Mo-O distances to the framework oxygens on Silicalite-1 however allude to a weaker interaction of Mo with this support. DFT calculations are in agreement with the experimental refinement, suggesting that Mo in Mo/Silicalite-1 it is not exclusively bound across silanol defect sites of the Silicalite- 1 support and attaches to the zeolite walls through oxygen atoms via electrostatic interaction.

The formation of analogous tetrahedral Mo-oxo sites upon calcination catalysts allows us to compare the catalytic activity of both catalysts and to discriminate between the roles of Mo structure, framework $\mathrm{Al}$ and BAS on MDA reaction. The activity studies showed benzene formation in both catalysts. In contrast with the traditionally postulated bifunctional mechanism, the aromatisation observed for $\mathrm{Mo} /$ Silicalite- 1 indicates that the presence of BAS is not essential for the formation of benzene. Therefore, molybdenum carbide species seem to promote aromatisation provided that good initial Mo dispersion into the zeolite pores ensures the shape selectivity to aromatics. These results are in agreement with Kosinov et al. who proposed that the conversion of methane to benzene might take place in a monofunctional manner on Mo carbides ${ }^{[19]}$ in the zeolite micropores, or mediated by carbonaceous species. ${ }^{[20,36]}$ Such mechanisms open the possibility to optimise active MDA catalysts based on non-acidic zeolites. These supports exhibit enhanced thermal stabilities that represent an advantage for the MDA reaction, which operates $>700{ }^{\circ} \mathrm{C}$ and is equilibrium-limited to $14 \%$ at $700{ }^{\circ} \mathrm{C}$, allowing to increase the reaction temperature for improved yields.

While the presence of BAS associated to framework $\mathrm{Al}$ is not required for aromatisation to occur, our research suggest that $\mathrm{Al}$ plays an important role on the stabilisation of Mo species. The 
shorter induction period for Mo/Silicalite-1 alludes to a more rapid carburisation of the initial Mo-oxo species. In line, a faster Mo sintering under reaction conditions and severe catalyst deactivation is also seen for this catalyst. These observations can be attributed to the weaker interaction of Mo species with the purely siliceous Silicalite- 1 evidenced by EXAFS and DFT. As proposed in our previous studies, such carburisation and sintering comprise the migration of Mo to the zeolite outer surface; this leads to the loss of shape electivity to aromatics provided by the pores and extensive accumulation of bulky carbon deposits in the zeolite outer surface. The characterisation carried out for reacted $\mathrm{Mo} / \mathrm{MFI}$ samples suggest a more pronounced sintering of molybdenum on Silicalite-1. The increased accumulation of carbon deposits is concluded from the $\mathrm{N}_{2}$ physisorption and TGA; Raman spectra indicate the deposits consist of disordered graphitic carbon, with a lower degree of crystallinity for $\mathrm{Mo} / \mathrm{Silicalite-1.} \mathrm{TEM-EDX}$ maps on $10 \mathrm{~h}$ reacted Mo/Siliclaite-1 show high $\mathrm{C}$ concentration in the zeolite outer surface.

The structure and location of Mo species clearly have a strong impact on catalytic performance. In this regard, framework Al seems to contribute to the stabilisation of Mo species resulting in a delayed catalyst deactivation. In this sense promising engineering solutions are being investigated by several groups to remove carbon deposits (i.e. through catalyst regeneration cycles or by using membrane reactors)..$^{44,14,37-40]}$ Nonetheless, an alternative approach to prevent deactivation would comprise the optimisation of the catalyst formulation, focused on further improving the stability of the active metal species inside the zeolite pores. In this line, follow up investigations should focus on enhancing the interaction of the active metal and the support on MDA catalysts.

\section{Experimental Section}

\section{Catalyst preparation}

Silicalite-1 (MFI structure, Si/Al $=\infty)$, was prepared by hydrothermal synthesis as described by Lobo et al. ${ }^{[41]}$ and subsequently calcined at $550{ }^{\circ} \mathrm{C}$. The resulting zeolite was then treated with ethylenediamine following the procedure reported by Wang et al. ${ }^{[42]}$ in order to generate silanol groups in the structure by the extraction of framework $\mathrm{Si}^{4+}$. ZSM-5 (also MFI structure, $\mathrm{Si} / \mathrm{Al}=15)$ was purchased from Zeolyst $(\mathrm{CBV} 3024 \mathrm{E})$ in its ammonium form. The proton form was obtained by calcination in static air at $550^{\circ} \mathrm{C}$ for $6 \mathrm{~h}$, the heating rate used was $2^{\circ} \mathrm{C} / \mathrm{min}$. $\mathrm{Mo} /$ Silicalite- 1 and Mo/H-ZSM-5 with metal loadings of $\sim 4$ wt. \% were prepared by first mixing the zeolite and $\mathrm{MoO}_{3}$ (Sigma, $99.95 \%)$ powders in an agate mortar for $0.5 \mathrm{~h}$. The resulting physical mixtures are referred to as the as-prepared catalysts. The samples were then calcined in air to $700 \stackrel{\circ}{ } \mathrm{C}$ for $0.5 \mathrm{~h}$ with a 5 ${ }^{\circ} \mathrm{C} / \mathrm{min}$ heating rate.

\section{Catalyst characterisation}

Fourier-transform infrared spectroscopy (FTIR) spectra were recorded in a Nicolet iS10 spectrometer. Samples were pressed into self-supporting wafers with a density of c.a. $10 \mathrm{mg} / \mathrm{cm}^{2}$. The wafers were dried prior to the measurements by heating them up to $285^{\circ} \mathrm{C}$ for $3 \mathrm{~h}$ under $70 \mathrm{ml} / \mathrm{min}$ He flow. After dehydration, the sample was cooled down to $150{ }^{\circ} \mathrm{C}$ under dry He before spectra collection. Temperature programmed desorption of ammonia ( $\mathrm{NH}_{3}$-TPD) was performed using an AutoChem II 2920 micromeritics instrument equipped with a moisture trap and a thermo-conductivity detector. Samples were first preactivated by flowing pure $\mathrm{N}_{2}$ and heating up to $550^{\circ} \mathrm{C}$ for $30 \mathrm{~min}\left(5^{\circ} \mathrm{C} / \mathrm{min}\right)$. The reactor was then cooled down to $100{ }^{\circ} \mathrm{C}$ for ammonia adsorption which was run by flowing $1 \% \mathrm{NH}_{3} / \mathrm{N}_{2}$ until saturation $(\sim 1 \mathrm{~h})$. Next, pure $\mathrm{N}_{2}$ was flowed for $2 \mathrm{~h}$ to remove physisorbed ammonia on the sample. Finally, ammonia desorption was carried out by increasing the temperature up to $1100{ }^{\circ} \mathrm{C}$ with a heating rate of $10^{\circ} \mathrm{C} / \mathrm{min}$. Powder X-ray diffraction (XRD) patterns were recorded using a Rigaku SmartLab X-Ray Diffractometer fitted with a hemispherical analyser. The measurements were performed using $\mathrm{Cu} \mathrm{Ka}$ radiation source $(\lambda=1.5406 \AA)$ with a voltage of $40 \mathrm{kV}$, and a current of $30 \mathrm{~mA}$. The patterns obtained were compared to crystallographic data in the reference library (ICSD database). Elemental analysis was carried out using inductively coupled plasma optical emission spectroscopy (ICP-OES) in a Perkin Elmer Optical Emission Spectrometer Optima 3300 RL. Nitrogen physisorption measurements were performed on a Quadrasorb EVO QDS-30 instrument at $77.3 \mathrm{~K}$. The samples were outgassed at $350 \stackrel{\circ}{ } \mathrm{C}$ overnight under vacuum prior to $\mathrm{N}_{2}$ sorption. The Brunauer-Emmett-Teller equation was used to calculate the specific surface area in the pressure range $p / p_{0}=0.0006-0.01$. The micropore volume was calculated from the t-plot curve using the thickness range between 3.5 and $5.4 \AA$. Thermogravimetric analysis (TGA) was carried out in a TA Q50 instrument. Samples were heated up to $950{ }^{\circ} \mathrm{C}$ using a rate of $5{ }^{\circ} \mathrm{C} / \mathrm{min}$ under an air flow of $60 \mathrm{~mL} / \mathrm{min}$. Raman spectra were acquired on ULTRA at the Central Laster Facility. ${ }^{[43][44]}$ The measurements were carried out using $400 \mathrm{~nm}$ laser to excite the sample (placed in quartz window holders). Toluene impregnated H-ZSM-5 was used for calibration of the detected signals. Scanning electron microscopy (SEM) analysis was performed using a Zeiss ultra 55 Field emission electron microscope. Compositional analysis and lowresolution imaging were carried out with accelerating voltage of $20 \mathrm{kV}, 30-60 \mu \mathrm{m}$ aperture and 7-8 mm working distance. Highresolution images were also taken with an accelerating voltage of $1.6 \mathrm{kV}, 20-30 \mu \mathrm{m}$ aperture and 2-3 mm working distance. Transmission electron microscopy (TEM) measurements were performed in a JEM 2800 (Scanning) with a voltage of $200 \mathrm{kV}$ and aperture of 70 and $40 \mu \mathrm{m}$. Bright-field imaging mode was performed using a CCD in high magnification, whereas lattice resolution imaging mode was carried out using CCD Dark-field (Zcontrast) imaging in scanning mode using an off-axis annular detector. The secondary electron signal was acquired simultaneously with the other TEM images providing topological information of the sample. Compositional analysis was performed by $\mathrm{X}$-ray emission detection in scanning mode.

\section{X-ray absorption spectroscopy during in situ calcination}


XAFS studies on Mo/MFI zeolites were carried out at the B18 beamline at Diamond Light Source ${ }^{[45]}$ in Harwell, United Kingdom. The storage beam energy was $3 \mathrm{GeV}$ and the ring current 300 $\mathrm{mA}$. Mo K-edge spectra (in the range of 19,797 to $21,000 \mathrm{eV}$ ) were collected in transmission mode using ion chamber detectors with a fast scanning Si (1 1 1 1) double crystal monochromator, with a Mo foil placed between It and Iref. X-ray beam dimensions at the sample position were $1 \times 1 \mathrm{~mm}^{2}$, whereas the acquisition of each spectra took $\sim 60 \mathrm{~s}$. In situ experiments were performed using a setup developed by A. B. Kroner et al.[46] For the experiments, $40 \mathrm{mg}$ of the as-prepared catalysts (sieve fractions: $0.425-0.150 \mathrm{~mm}$ ) were placed in a $3 \mathrm{~mm}$ diameter quartz capillary The sample was then heated to $700 \stackrel{\circ}{\circ}$ for 30 min using a hot gas blower, under $20 \% \mathrm{O}_{2}$ in He flow (GHSV $=3000 \mathrm{~h}^{-1}$ and heating rate $=5{ }^{\circ} \mathrm{C} / \mathrm{min}$ ). After $30 \mathrm{~min}$, the sample was cooled to room temperature under pure $\mathrm{He}$. XAS data was collected during the heating ramp as well when back at room temperature after calcination.

XAS data analysis was performed using the Demeter software package. ${ }^{[47]}$ The $X$-ray absorption fine structure (EXAFS) fitting to model spectra was done using an amplitude reduction factor of 0.91 , which was obtained by fitting the Mo foil reference to crystallographic data from the ICSD database. $\mathrm{K}$ range values used in the fitting were between 3 and $11 \AA^{-1}$ whereas the $R$ range spanned 1 to $3 \AA$ were used. The Mo K-edge edge position was taken as the energy at half-step height and the Fourier transformed (FT) EXAFS data presented are not phase corrected.

\section{Density functional theory}

Based on our EXAFS studies on Mo/zeolites, ${ }^{[23]}$ only monomeric species were considered in the calculations. All the calculations were performed at $0 \mathrm{~K}$.

The initial computational component involved the geometry optimisation of a single orthorhombic MFI unit cell with $\mathrm{Si} / \mathrm{Al}=\infty$ (i.e. Silicalite-1), obtained from the IZA zeolite structure database, ${ }^{[48]}$ using $\mathrm{CP} 2 \mathrm{~K}^{[49]}$ at the $\mathrm{PBE}{ }^{[50]}$ level of theory with a DZVP-MOLOPT basis. To give a sensible starting geometry for monomeric $\left[\mathrm{MoO}_{4}\right]^{2-}$, molybdate (known to have a similar structure to $\left.\left[\mathrm{MoO}_{4}\right]^{2-}\right)$ was geometry optimised as an isolated cluster using the Orca code (PBE functional and SVP basis). Then $\left[\mathrm{MoO}_{2}\right]^{2+}$ was grafted to two framework oxygen atoms $\left(\mathrm{O}_{\mathrm{F}}\right)$ across the T5 site forming $[\mathrm{MoO} 4]^{2-}$. This structure was geometry optimised at the same level of theory as the empty Silicalite-1 framework. Mo interaction with different possible types silanols i.e. nests, vicinal and geminal, was also simulated. For the nests, Si was removed from the T5 sites in the initial empty Silicalite-1 structure satisfying the four dangling $\mathrm{Si}-\mathrm{O}$ bonds generated with terminating protons. The resultant structure was then geometry optimised at the same level of theory used throughout. Following this, $\left[\mathrm{MoO}_{2}\right]^{2+}$ was re-introduced to the same position as before, removing the two protons from the framework oxygens bound to Mo in order to mimic the condensation reaction that is proposed to occur when the initial mobile Mo-oxo species. Vicinal and nonvicinal silanol defects were simulated by removing Si from the T5 and $\mathrm{T} 9$ sites in both the vicinal and non-vicinal case. $\left[\mathrm{MoO}_{2}\right]^{2+}$ was then grafted across the defects, removing two protons to mimic condensation reactions. The two structures were geometry optimised at the same level of theory used throughout these simulations.

Finally, the Mo/Silicalite-1 models were compared with that of Mo/ZSM-5 by introducing a single Al to each of the 12 crystallographically distinct framework $T$-site present in orthorhombic MFI. Brønsted acidic protons were not included in these simulations in order to mimic the liberation of water which is proposed to occur on binding of the initial Mo-oxo species to the walls of the framework. The Mo-oxo species in H-ZSM-5 remained in the same position, grafted across the T5 site.

\section{MDA catalytic performance tests}

$0.6 \mathrm{~g}$ of sieved catalyst (150-425 $\mu \mathrm{m}$ sieve fraction) was introduced into a tubular quartz reactor (internal diameter $=0.7$ $\mathrm{mm}$ ). The sample was fixed in the isothermal zone of the oven by quartz wool. A total gas flow of $30 \mathrm{~mL} / \mathrm{min}$ was fed by means of mass flow controllers $\left(\mathrm{GHSV}=1500 \mathrm{~h}^{-1}\right)$.

The as-prepared physical mixtures were first calcined under $20 \%$ $\mathrm{O}_{2} / \mathrm{He}$ flow by heating up to $700^{\circ} \mathrm{C}$ for $30 \mathrm{~min}$ using a heating rate of $5{ }^{\circ} \mathrm{C} / \mathrm{min}$. After flowing pure $\mathrm{Ar}$ for $30 \mathrm{~min}$, methane dehydroaromatisation reaction was initiated by flowing $50 \%$ $\mathrm{CH}_{4} / \mathrm{Ar}$. The reaction products were analysed by an online mass spectrometer (OmniStar GSD 32001). All MS data intensity presented in this manuscript are normalised to the Ar signal and are plotted in logarithmic scale.

To follow the deactivation process, Mo/MFI samples were collected at different reaction times ( $7 \mathrm{~min}, 90 \mathrm{~min}$ and $10 \mathrm{~h}$ ) after cooling down the reactor under Ar flow. The resulting samples are denoted by adding the reaction time after the sample code. For example, Mo/Silicalite- 1 sample reacted for $90 \mathrm{~min}$ is identified as $\mathrm{Mo} /$ Silicalite-1(90min).

\section{Acknowledgements}

This study received financial support from EPSRC (MAA, a UCL Impact PhD award, Diamond Light Source and Johnson Matthey). EPSRC is also acknowledged for sponsoring the UK Catalysis Hub which provided resources and support via grant, EP/K014714/1 and for an Early Career Fellowship for AMB (EP/K007467/1). This research used resources from RCaH and Johnson Matthey Technology Centre. Diamond Light Source is kindly thanked for the awarded beamtime (SP11623) whereas Diego Gianolio, Emma Gibson, Scott Rogers and George Tierney are kindly acknowledged for the assistance during the synchrotron experiments. Nicolas Grosjean is also acknowledged for the assistance during catalytic testing.

\section{Keywords: MDA • Mo/zeolite • in situ XAS • DFT}
[1] B. M. Weckhuysen, D. Wang, M. P. Rosynek, J. H. Lunsford, J. Catal. 1998, 175, 347-351.
[2] S. Ma, X. Guo, L. Zhao, S. Scott, X. Bao, J. Energy Chem. 2013, 22, 1-20.
[3] Z. R. Ismagilov, E. V. Matus, L. T. Tsikoza, Energy Environ. Sci. 
2008, 1, 526-541.

[4] J. J. Spivey, G. Hutchings, Chem. Soc. Rev. 2014, 43, 792-803.

[5] F. Solymosi, J. Cserényi, A. Szöke, T. Bánsági, A. Oszkó, J. Catal. 1997, 165, 150-161.

[6] Y. Xu, Y. Shu, S. Liu, J. Huang, X. Guo, Catal. Letters 1995, 35, 233-243.

[7] C. H. L. Tempelman, E. J. M. Hensen, Appl. Catal. B Environ. 2015, 176-177, 731-739.

[8] C. Karakaya, H. Zhu, R. J. Kee, Chem. Eng. Sci. 2014, 123, 474486.

[9] K. S. Wong, J. W. Thybaut, E. Tangstad, M. W. Stöcker, G. B. Marin, Microporous Mesoporous Mater. 2012, 164, 302-312.

[10] D. Ma, Y. Shu, M. Cheng, Y. Xu, X. Bao, J. Catal. 2000, 194, 105114.

[11] J. Shu, A. Adnot, B. P. A. Grandjean, Ind. Eng. Chem. Reseacrh 1999, 38, 3860-3867.

[12] A. Sarıog, A. Mer, T. Savaçı, A. Aye, E.-E. Ae, V. Thu, H. Ae, G. Sapaly, A. Younès, B. Taârit, Catal. Letters 2007, 118, 123-128.

[13] S. Liu, L. Wang, R. Ohnishi, M. Ichikawa, J. Catal. 1999, 181, 175188.

[14] H. S. Lacheen, E. Iglesia, Phys. Chem. Chem. Physiscs 2005, 7, 538-547.

[15] M. Marczewski, H. Marczewska, K. Mazowiecka, React. Kinet. Catal. Lett 1995, 54, 81-86.

[16] J. P. Tessonnier, B. Louis, S. Rigolet, M. J. Ledoux, C. Pham-Huu, Appl. Catal. A Gen. 2008, 336, 79-88.

[17] F. Solymosi, A. Erd6helyi, A. Sz6ke, Catal. Letters 1995, 32, 43-53.

[18] X. Guo, G. Fang, G. Li, H. Ma, H. Fan, L. Yu, C. Ma, X. Wu, D. Deng, M. Wei, et al., Science 2014, 344, 616-619.

[19] N. Kosinov, F. J. A. G. Coumans, E. A. Uslamin, A. S. G. Wijpkema, B. Mezari, E. J. M. Hensen, ACS Catal. 2017, 7, 520-529.

[20] N. Kosinov, A. Wijpkema, E. Uslamin, R. Rohling, F. Coumans, B. Mezari, A. Parastaev, A. Poryvaev, M. Fedin, E. Pidko, et al., Angew. Chemie 2018, 57, 1016-1020.

[21] N. Kosinov, A. E. Uslamin, J. A. G. F. Coumans, S. G. A. Wijpkema, Y. R. Rohling, J. M. E. Hensen, ACS Catal. 2018, 8, 8459-8467.

[22] I. Lezcano-González, R. Oord, M. Rovezzi, P. Glatzel, S. W. Botchway, B. M. Weckhuysen, A. M. Beale, Angew. Chemie - Int. Ed. 2016, 55, 5215-5219.

[23] M. Agote-Arán, A. B. Kroner, H. U. Islam, W. A. Sławin, D. S. Wragg, I. Lezcano-González, ChemCatChem 2019, 11, 473-480.

[24] S. E. Shadle, B. Hedman, K. Hodgson, E. I. Solomon, Inorg. Chem. 1994, 33, 4235-4244.

[25] W. Li, G. D. Meitzner, R. W. Borry, E. Iglesia, J. Catal. 2000, 191, 373-383.

[26] C. Brookes, P. P. Wells, G. Cibin, N. Dimitratos, W. Jones, D. J. Morgan, M. Bowker, ACS Catal. 2014, 4, 243-250.

[27] H. Negishi, S. Negishi, Y. Kuroiwa, N. Sato, S. Aoyagi, Phys. Rev. B 2004, 69, 064111
[28]

[29]

[30]

[31]

[32]

(1)

D. Zhou, D. Ma, X. Liu, X. Bao, J. Chem. Phys. 2001, 114, 91259129.

H. Guesmi, R. Gryboś, J. Handzlik, F. Tielens, Phys. Chem. Chem. Phys. 2014, 16, 18253-18260.

C. A. Johnson, K. M. Thomas, FUEL 1984, 63, 1073-1080.

P. K. Chu, L. Li, Mater. Chem. Phys. 2006, 96, 253-277.

A. C. Ferrari, J. Robertson, Phys. Rev. B 2000, 61, 14095-14107.

A. Sadezky, H. Muckenhuber, H. Grothe, R. Niessner, U. Pö Schl, Carbon N. Y. 2005, 43, 1731-1742.

J. Hoekstra, A. M. Beale, F. Soulimani, M. Versluijs-Helder, J. W. Geus, L. W. Jenneskens, J. Phys. Chemsitry 2015, 119, 1065310661.

B. Dippel, H. Janderb, J. Heintzenberga, Phys. Chem. Chem. Phys. 1999, 1, 4707-4712.

I. Vollmer, G. Li, I. Yarulina, N. Kosinov, E. J. Hensen, K. Houben, D. Mance, M. Baldus, J. Gascon, F. Kapteijn, Catal. Sci. Technol. 2018, 8, 916-922.

N. Kosinov, F. J. A. G. Coumans, G. Li, E. Uslamin, B. Mezari, A. S. G. Wijpkema, E. A. Pidko, E. J. M. Hensen, J. Catal. 2017, 346, 125-133.

Y. H. Kim, R. W. Borry, E. Iglesia, Microporous Mesoporous Mater. 2000, 35-36, 495-509.

H. Ma, R. Kojima, R. Ohnishi, M. Ichikawa, Appl. Catal. A Gen. 2004, 275, 183-187.

S. H. Morejudo, R. Zanón, S. Escolástico, I. Yuste-Tirados, H. Malerød-Fjeld, P. K. Vestre, W. G. Coors, A. Martínez, T. Norby, J. M. Serra, et al., Science (80-. ). 2016, 353, 563-566.

1] D. D. Kragten, J. M. Fedeyko, K. R. Sawant, J. D. Rimer, D. G. Vlachos, R. F. Lobo, M. Tsapatsis, J. Phys. Chem. B 2003, 107, 10006-10016.

[42] Y. Bu, Y. Wang, Y. Zhang, L. Wanga, Z. Mi, W. Wub, E. Min, S. Fu, Catal. Commun. 2007, 8, 16-20.

"CLF Ultra," can be found under https://www.clf.stfc.ac.uk/Pages/Ultra.aspx, n.d. P. Matousek, M. Towrie, C. Ma, W. M. Kwok, D. Phillips, W. T. Toner, A. W. Parker, J. Raman Spectrosc. 2001, 32, 983-988. A. J. Dent, G. Cibin, S. Ramos, A. D. Smith, S. M. Scott, L. Varandas, M. R. Pearson, N. A. Krumpa, C. P. Jones, P. E. Robbins, J. Phys. Conf. Ser 2009, 190, 012039.

A. B. Kroner, K. M. H. Mohammed, M. Gilbert, G. Duller, L. Cahill, P. Leicester, R. Woolliscroft, E. J. Shotton, AIP Conf. Proc. 2016, 1741, 030014.

B. Ravel, M. Newville, J. Synchrotron Radiat. 2005, 12, 537-541. Www.lza-Structure.Org, n.d., 01, 212-213.

J. VandeVondele, M. Krack, F. Mohamed, M. Parrinello, T. Chassaing, J. Hutter, Comput. Phys. Commun. 2005, 167, 103-128. J. P. Perdew, K. Burke, M. Ernzerhof, Phys. Rev. Lett. 1996, 78, 1396-1396. 


\section{FULL PAPER}

X-ray absorption spectroscopy and density functional theory calculations were performed to investigate the Mo structure on Mo/Silicalite-1 $(\mathrm{Si} / \mathrm{Al}=\infty)$ and Mo/H-ZSM-5 (Si/Al=5) catalysts. These studies combined with catalytic activity measurements bring new insight to unravel the roles of Mo speciation, framework $\mathrm{Al}$ and Brønsted acid sites on the methane dehydroaromatisation reaction.

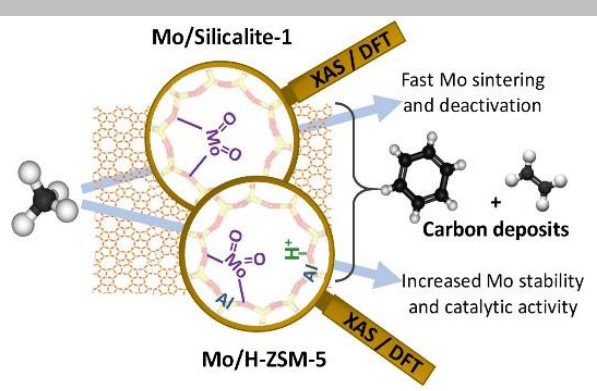

Miren Agote-Arán, Rachel E. Fletcher, ${ }^{[a]}$ Martha Briceno, Anna B. Kroner, ${ }^{[b]}$ Igor V. Sazanovic, Ben Slater, ${ }^{[a]}$ María E. Rivas, Andrew W.J. Smith, ${ }^{[c]}$ Paul Collier, Inés Lezcano-González, *Andrew M. Beale*

Page No. - Page No.

Implications of the Molybdenum

Coordination Environment in MFI

Zeolites

on

Methane

Dehydroaromatisation 